\title{
Rofecoxib does not compromise platelet aggrega- tion during anesthesia and surgery
}

\section{[Le rofécoxib n'altère pas l'agrégation plaquettaire pendant l'anesthésie et la chirurgie]}

\author{
David G. Silverman MD, Thomas Halaszynski MD, Raymond Sinatra MD PhD, Martha Luther MPH,
} Christine S. Rinder MD

Purpose: This study was undertaken because, although there is evidence that cyclooxygenase type 2 (COX)-2 inhibitors do not compromise platelets in healthy volunteers, many clinicians remain hesitant to administer them perioperatively without definitive evidence of intact platelet function during anesthesia and surgery.

Methods: In 20 patients scheduled for lower abdominal and pelvic surgery, $5 \mathrm{~mL}$ of blood were obtained for baseline platelet aggregometry. One hour prior to surgery, patients received an oral solution of either rofecoxib (ROF) $50 \mathrm{mg}$ or placebo (PLAC) by randomized, double-blinded assignment. Approximately one hour after onset of anesthesia, an intraoperative blood sample was obtained.

Baseline and postdrug samples were centrifuged to generate platelet-rich plasma, which was challenged with adenosine diphosphate (ADP) and arachidonic acid (AA). Aggregometry was performed with and without incubation with aspirin. The data in each subject were normalized to baseline aggregation in response to AA alone and ADP alone. Intergroup differences were assessed using paired t test; $P<0.05$ was considered significant.

Results: Consistent with known effects of anesthesia on platelet function, both groups had approximately $25 \%$ intraoperative declines in aggregation in response to ADP ( $P=$ NS for PLAC vs ROF) and even greater declines in response to $A A(P=N S$ for $P L A C$ vs ROF). Aspirin eliminated aggregation in response to $A A$ in both groups $(P=N S)$, and it caused similar declines in PLAC and ROF groups during exposure to ADP ( $P=N S)$.

Conclusion: This study provides strong evidence that ROF does not compromise platelet aggregation during anesthesia and surgery; nor does it interfere with the platelet inhibitory effect of aspirin.

Objectif: Nous avons réalisé la présente étude parce que, même s'il y a une évidence que les inhibiteurs de la cyclo-oxygénase de type 2 (COX)-2 n'altèrent pas les plaquettes chez des volontaires en bonne santé, de nombreux cliniciens hésitent encore à les administrer en période périopératoire sans avoir la preuve irréfutable de la conservation de la fonction plaquettaire pendant l'anesthésie et la chirurgie.
Méthode : Nous avons prélevé $5 \mathrm{~mL}$ de sang, pour une agrégométrie plaquettaire de base, chez 20 patients devant subir une opération pelvienne et abdominale basse. Une heure avant l'opération, une solution orale de $50 \mathrm{mg}$ de rofécoxib (ROF) ou d'un placebo (PLAC) ont été administrés de façon aléatoire et en double insu. Une heure environ après le début de l'anesthésie, un échantillon de sang a été prélevé.

Les échantillons de base et les prélèvements suivant la médication ont été centrifugés pour générer un plasma riche en plaquettes, lequel a été stimulé avec de l'adénosine diphosphate (ADP) et de l'acide arachidonique (AA). L'agrégométrie a été réalisée avec et sans incubation avec aspirine. Les données sur chaque sujet ont été normalisées à partir de l'agrégation de base en réaction à l'AA seule et l'ADP seule. Les différences intergroupes ont été évaluées par le test $t$ pour des paires d'échantillons ; $P<0,05$ était considéré comme significatif.

Résultats : Conformément aux effets connus de l'anesthésie sur la fonction plaquettaire, il y a eu dans les deux groupes environ $25 \%$ de diminution peropératoire de l'agrégation en réaction à l'ADP $(P=N S$ pour le PLAC vs ROF) et une baisse encore plus grande en réaction à I'AA ( $P=N$ S pour le PLAC vs ROF). L'aspirine a éliminé l'agrégation en réaction à l'AA dans les deux groupes ( $P=N S)$ et a causé une diminution similaire dans les groupes PLAC et ROF pendant l'exposition à l'ADP $(P=N S)$.

Conclusion : L'étude fournit une indication claire que la ROF n'altère pas l'agrégation plaquettaire pendant l'anesthésie et la chirurgie ; elle ne nuit pas non plus à l'effet inhibiteur de l'aspirine.

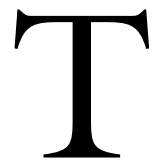

HE development of selective cyclooxygenase type 2 (COX-2) inhibitors has been prompted by the desire to obtain the antiinflammatory and analgesic effects of nonsteroidal anti-inflammatory drugs (NSAIDs) without the unwanted COX-1 inhibitory effects of nonselective NSAIDs. Trials in otherwise unmedicated volun-

From the Departments of Anesthesiology and Laboratory Medicine, Yale University School of Medicine, New Haven, Connecticutt, USA. Address correspondence to: Dr. David G. Silverman, Department of Anesthesiology, Yale University School of Medicine, 333 Cedar

Street, New Haven, CT 06520-8051, USA. Phone 203-785-2802; Fax: 203-785-6664; E-mail david.silverman@yale.edu

Supported by NIH Grant HL-47193 (Dr. Rinder) and Merck \& Co., Inc.

Accepted for publication March 13, 2003.

Revision accepted September 3, 2003. 
teers and nonsurgical patients have indicated that COX-2 inhibitors have virtually no effect on the gastric mucosa or platelet function. ${ }^{1-4}$ Safety in the perioperative setting has been suggested by the lack of increased intraoperative blood loss in patients receiving this class of drug. ${ }^{5,6}$

Despite these favourable findings, many clinicians remain hesitant to administer COX-2 inhibitors perioperatively until there is more definitive evidence that these drugs do not alter platelet function during anesthesia and surgery. Such evidence may be provided by measuring platelet aggregation ${ }^{2,7,8}$ in response to an aggregatory stimulus such as arachidonic acid (AA) or adenosine diphosphate (ADP). Whereas a myriad of potentially offsetting perioperative factors - many of which are not directly related to platelet function may affect measurements of blood loss, aggregometry is more sensitive to and more specific for the potential platelet inhibitory effects of a study drug. The present investigation addressed the potential for a COX-2 effect on perioperative platelet function by testing the hypothesis that, in the context of anesthesia and surgery, pretreatment with rofecoxib (ROF; Vioxx, Merck \& Co., Inc, West Point, PA, USA) would not alter platelet aggregation in response to an aggregatory challenge.

\section{Methods}

With Institutional Review Board approval, 20 consecutive patients scheduled for elective lower abdominal or pelvic surgery were asked to provide informed written consent for this double-blinded study. Exclusion criteria included use of aspirin-based products, NSAIDs or other antiplatelet medications within ten days of baseline testing or surgery, use of alcohol within three days, history of bleeding diathesis or gastrointestinal bleeding, pregnancy, renal insufficiency, or known allergy to NSAIDs.

At the time of recruitment, $5 \mathrm{~mL}$ of blood were obtained for baseline (preoperative) platelet aggregometry. On the morning of surgery, patients received either $50 \mathrm{mg}(10 \mathrm{~mL})$ of ROF oral suspension or 10 $\mathrm{mL}$ of placebo suspension (PLAC), based on a randomized, double-blinded assignment. Randomization was achieved by computer-generated assignment of sequential patients. The $50 \mathrm{mg}$ dose was selected to be consistent with recommended doses of ROF for acute pain $^{9,10}$ and premedication. ${ }^{11-13}$

One hour after ROF or PLAC administration, anesthesia was initiated. One hour later - approximately two hours after administration of the study drug - a postdrug sample was obtained. The time interval for blood sampling was selected based upon documentation of analgesic efficacy within $45 \mathrm{~min}$ of oral ingestion of ROF $50 \mathrm{mg}$ in patients experiencing dental pain ${ }^{9}$ and within 75 min in patients receiving analgesia and sedation for nasal surgery, ${ }^{13}$ as well as documentation of significant plasma levels by two hours after ingestion (with virtual bioequivalence of ROF in oral suspension and tablets). ${ }^{14}$

The baseline (pre-study drug) and intraoperative (post-study drug) blood samples were prepared identically to generate platelet-rich plasma, which was adjusted to a platelet count of $250 \times 10^{9} \cdot \mathrm{L}^{-1}$ as previously described. ${ }^{8}$ Aggregometry was performed on separate aliquots of platelet-rich plasma stimulated with ADP $10 \mu \mathrm{M}$ or AA $1.66 \mu \mathrm{M}$; the maximum amplitude of each response was recorded. For a positive control, a separate plasma aliquot was incubated with $500 \mu \mathrm{M}$ aspirin; ${ }^{8}$ then aggregometry was repeated with ADP or AA as above.

Based on previous studies of the effects of NSAIDs on intraoperative aggregometry, ${ }^{15}$ it was determined that 20 patients would be sufficient to detect a difference between treatment groups with a power $>0.80$ and an alpha of $<0.05$. The data from each subject were normalized to the baseline preoperative aggregation response to ADP or AA alone. Inter-group differences were assessed using an unpaired t test; $P<$ 0.05 was considered statistically significant. Patients who failed at baseline (prior to study drug ingestion) to aggregate in response to ADP or AA (<10\% aggregation) were excluded from analysis.

\section{Results}

The two groups were similar with respect to mean age and weight. The anesthetics, which included agents with documented effects on platelet function, ${ }^{7,15-19}$ did not differ significantly between the two groups $(P=\mathrm{NS})$. Nine ROF and six PLAC patients received midazolam in doses $($ mean $\pm \mathrm{SD}$ ) of $1.9 \pm 0.3$ and $1.7 \pm 0.5 \mathrm{mg}$, respectively. Nine ROF and nine PLAC patients received propofol in respective doses of $157.5 \pm 68$ and $198.9 \pm$ $41 \mathrm{mg}$. Five ROF and four PLAC patients received sevoflurane; no patient received halothane which, like sevoflurane, has been shown to affect platelet function. Overall, ten ROF and nine PLAC patients received an inhalational anesthetic. All 20 patients received fentanyl, in mean doses of $250.0 \pm 24$ and $193.8 \pm 95 \mu \mathrm{g}$ for ROF and PLAC patients, respectively.

All 20 patients completed the study. One subject in the ROF group was excluded from analysis because of failure to aggregate in response to AA at baseline (i.e., predrug). There was no evidence of increased bleeding in any of the patients. None of the subjects required administration of blood products. 


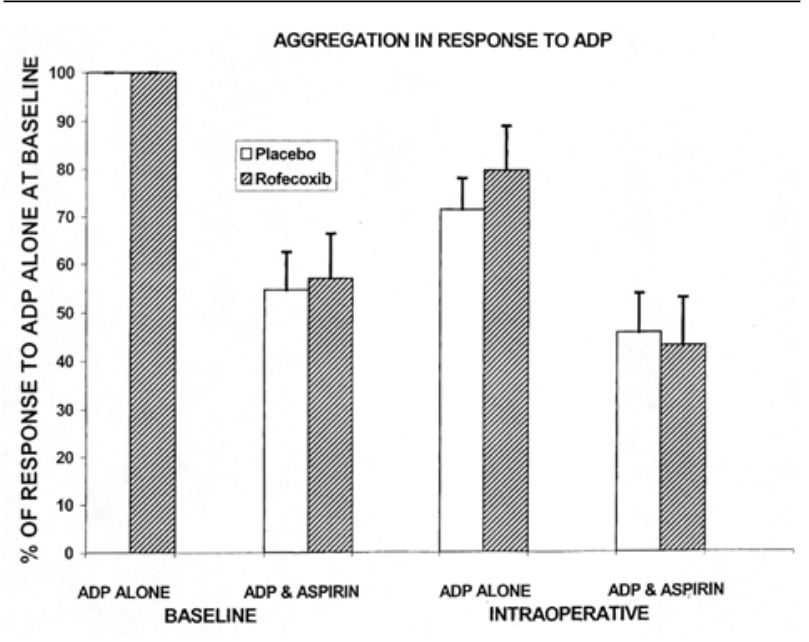

FIGURE 1 Responses to in vitro challenges with adenosine diphosphate (ADP), with and without incubation with aspirin. Data for each phase of testing normalized to value for the response to ADP alone in the given subject at baseline. Overall normalized data for each group presented as mean $\pm \mathrm{SE}$.

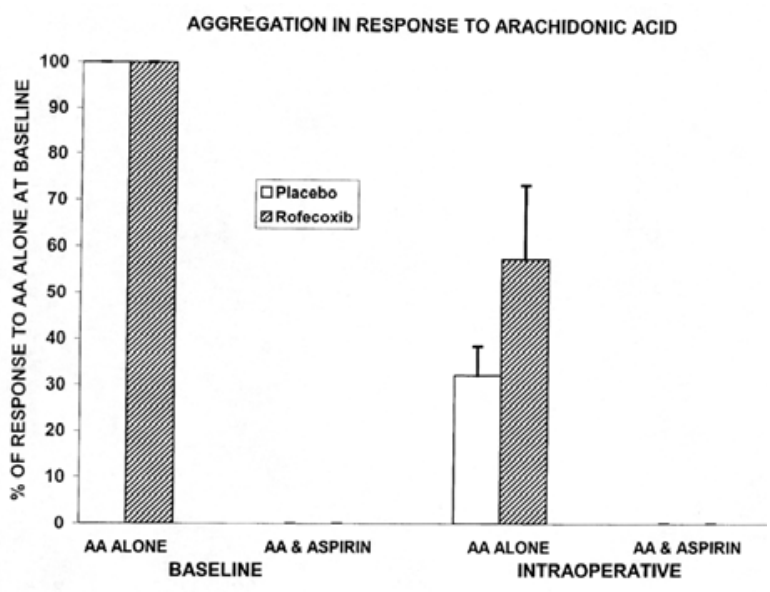

FIGURE 2 Responses to in vitro challenges with arachidonic acid (AA), with and without incubation with aspirin. Data for each phase of testing normalized to value for the response to AA alone in the given subject at baseline. Overall normalized data for each group presented as mean $\pm \mathrm{SE}$.

tions as generation of thromboxane (for vasoconstriction and platelet-derived hemostasis) and maintenance of gastrointestinal mucosal integrity. $3,4,20,23$

Although there is evidence as to the high platelet safety profile of selective COX-2 inhibitors, ${ }^{1,2}$ many clinicians remain concerned about these drugs in the perioperative setting. The aforementioned studies did not include the variables associated with surgical trauma or the potential effects of anesthesia. Such factors theoretically could uncover and/or lead to potential interactions with COX-2 inhibitors that might impair platelet function. Specifically, the declines in sympathoadrenal activity and stress hormone levels associated with anesthesia can affect platelet aggregation. . $^{84,25}$ Furthermore, it has been noted that inhalational agents such as halothane and sevoflurane suppress platelet aggregation and increase bleeding times by a variety of interacting mechanisms; and, by seemingly different mechanisms, midazolam and propofol also inhibit platelet aggregation. ${ }^{716-19}$ Our data are consistent with these findings in that the PLAC and ROF groups both had declines in aggregation intraoperatively. The similar declines after PLAC and ROF confirm that ROF does not compromise platelet aggregation in the context of "routine" anesthesia such as that employed in the present series; however, in that we sought to perform our assessments in the context of routine anesthetics, we did not focus on high doses of specific anesthetic agents. 
Incubation of platelet-rich plasma with aspirin in the present study has provided additional evidence as to the lack of an effect of ROF on platelet function. First, aspirin incubation served as a positive control to confirm the sensitivity of the present tests of aggregation to abrogated COX-1 activity. ${ }^{8,26}$ AA induces aggregation entirely via the aspirin-sensitive COX pathway; hence, aspirin eliminated the aggregation response to this stimulus. By contrast, ADP induces aggregation by the combined effects of direct binding to platelet ADP receptors, dense granule-derived serotonin and thromboxane $\mathrm{A}$, of which only the last is inhibited by aspirin. ${ }^{8}$ Second, the normal response to aspirin in the present study in samples from ROF and PLAC patients indicated that the use of ROF would not compromise the cardioprotective effect of aspirin therapy. This finding supports the clinical practice of restarting daily aspirin during the postoperative period without concern for decreased cardioprotective effects due to concurrent use of ROF. Conversely, pretreatment with a nonspecific NSAID causes patients to become "aspirin nonresponders" by rendering the active site of platelet COX-1 inaccessible to the aspirin during significant NSAID levels. ${ }^{27}$

It should be noted that, while the present study supports the perioperative safety of COX-2 inhibitors, it did not include patients with known alterations of platelet or endothelial function. Thus, conclusions as to the lack of an effect of selective COX-2 inhibition may not be wholly applicable to those patients. COX inhibitors affect hematological, endothelial, inflammatory, and algesic pathways. Such alterations of the counterbalancing roles of the products of COX-1 and COX-2 mediated processes (e.g., thromboxane and prostacyclin, respectively) may have greater impact on patients with preexisting abnormalities, especially when long-term therapy is employed..$^{22,28}$

In conclusion, the present data confirm the lack of an effect of ROF on intraoperative platelet function in patients undergoing typical anesthetics for lower abdominal and pelvic surgery. There was no suggestion of ROF-induced potentiation of anti-platelet effects or alteration of the effects of subsequent aspirin. The delineation of such safety with aggregometry should mitigate concerns about potential perioperative platelet dysfunction in patients receiving a brief course of a COX-2 inhibitor.

\section{References}

1 Weaver $A L$. Rofecoxib: clinical pharmacology and clinical experience. Clin Therap 2001; 23: 1323-38.

2 Rinder HM, Tracey JB, Soubrada M, Wang C, Gagnier $R P$, Wood CC. Effects of meloxicam on platelet function in healthy adults: a randomized, double-blind, placebocontrolled trial. J Clin Pharmacol 2002; 42: 881-6.

3 Warner TD, Giuliano F, Vojnovic I, Bukasa A, Mitchell $J A$, Vane JR. Nonsteroid drug selectivities for cyclooxygenase- 1 rather than cyclo-oxygenase- 2 are associated with human gastrointestinal toxicity: a full in vitro analysis. Proc Natl Acad Sci USA 1999; 96: 7563-8.

4 Laine L, Harper S, Simon T, et al. A randomized trial comparing the effect of rofecoxib, a cyclooxygenase 2specific inhibitor, with that of ibuprofen on the gastroduodenal mucosa of patients with osteoarthritis. Gastroenterology 1999; 117: 776-83.

5 Reuben SS, Connelly NR. Postoperative analgesic effects of celecoxib or rofecoxib after spinal fusion surgery. Anesth Analg 2000; 91: 1221-5.

6 Buvanendran A, Elmofty D, Tuman KJ, Sheinkop M, Kroin JS. Administration of selective cyclooxygenase-2 inhibitor with warfarin does not increase blood loss following total knee arthroplasty (TKA). Anesthesiology 2002; 96: 942 (abstract).

7 Faraday N. Platelets, perioperative hemostasis, and anesthesia. Anesthesiology 2002; 96: 1042-3.

8 Rinder CS, Student LA, Bonan JL, Rinder HM, Smith $B R$. Aspirin does not inhibit adenosine diphosphateinduced platelet $\alpha$-granule release. Blood 1993; 82: 505-12.

9 Chang DJ, Fricke JR Jr, Bird SR, Bobidar NR, Dobbins $T W$, Geba GP. Rofecoxib versus codeine/acetaminophen in postoperative dental pain: a double-blind, randomized, placebo- and active comparator-controlled clinical trial. Clin Ther 2001; 23: 1446-55.

10 Hawkey CJ. COX-2 inhibitors. Lancet 1999; 353: 307-14.

11 Issioni $T$, Klein KW, White PF, et al. Cost-efficacy of rofecoxib versus acetaminophen for preventing pain after ambulatory surgery. Anesthesiology 2002; 97: 931-7.

12 Shen Q, Sinatra $R$, Luther M, Halaszynski T.

Preoperative rofecoxib $25 \mathrm{mg}$ and $50 \mathrm{mg}$ : effects on post-surgical morphine consumption and effort dependent pain. Anesthesiology 2001; 95: 961 (abstract).

13 Turan A, Emet S, Karamanlioglu B, Memis D, Turan $N$, Pamukcu $Z$. Analgesic effects of rofecoxib in earnose-throat surgery. Anesth Analg 2002; 95: 1308-11.

14 Vioxx (rofecoxib tablets and oral suspension) product information. West Point, PA. Merck and Co., Inc, May 1999.

15 Thwaites BK, Nigus DB, Bouska GW, Mongan PD, Ayala EF, Merrill GA. Intravenous ketorolac tromethamine does not worsen platelet function during knee arthroscopy under general anesthesia. Anesth Analg 1995; 81: 119-24.

16 Aoki H, Mizobe T, Nozuchi S, Hiramatsu N. In vivo and in vitro studies of the inhibitory effect of propofol 
on human platelet aggregation. Anesthesiology 1998; 88: $362-70$

17 Nygard E, Naesh O, Hindberg I, Valentin N. Effect of nitrous oxide and volatile anaesthetics on platelet function in man. Acta Anaesthesiol Scand 1994; 38: 40-2.

18 Hirakata $H$, Ushikubi F, Toda $H$, et al. Sevoflurane inhibits human platelet aggregation and thromboxane $\mathrm{A}_{2}$ formation, possibly by suppression of cyclooxygenase activity. Anesthesiology 1996; 85: 1447-53.

19 Sheu JR, Hsiao G, Luk HN, et al. Mechanisms involved in the antiplatelet activity of midazolam in human platelets. Anesthesiology 2002; 96: 651-8.

20 McAdam BF, Catella-Lawson F, Mardini IA, Kapoor S, Lawson JA, FitzGerald GA. Systemic biosynthesis of prostacyclin by cyclooxygenase (COX)-2: the human pharmacology of a selective inhibitor of COX-2. Proc Natl Acad Sci USA 1999; 96: 272-7.

21 Ehrich EW, Dallob A, De Lepeleire I, et al. Characterization of rofecoxib as a cyclooxygenase- 2 isoform inhibitor and demonstration of analgesia in the dental pain model. Clin Pharmacol Ther 1999; 65: $336-47$.
22 FitzGerald GA, Patrono C. Drug therapy: the coxibs, selective inhibitors of cyclooxygenase-2. N Engl J Med 2001; 345: 433-42.

23 Schafer AI. Effects of nonsteroidal anti-inflammatory therapy on platelets. Am J Med 1999; 106: 25S-36S

24 Naesh O, Haedersdal C, Hindberg I, Trap-Jensen J. Platelet activation in mental stress. Clin Physiol 1993; 13: 299-307.

25 Rosenfeld BA, Faraday N, Campbell D, Dise K, Bell W, Goldschmidt P. Hemostatic effects of stress hormone infusion. Anesthesiology 1994; 81: 1116-26.

26 Patrignani P, Filabozzi P, Patrono C. Selective cumulative inhibition of platelet thromboxane production by low-dose aspirin in healthy subjects. J Clin Invest 1982; 69: 1366-72.

27 Catella-Lawson F, Reilly MP, Kapoor SC, et al. Cyclooxygenase inhibitors and the antiplatelet effects of aspirin. N Engl J Med 2001; 345: 1809-17.

28 Mukherjee D, Nissen SE, Topol EJ. Risk of cardiovascular events associated with selective COX-2 inhibitors. JAMA 2001 ; 286: 954-9.

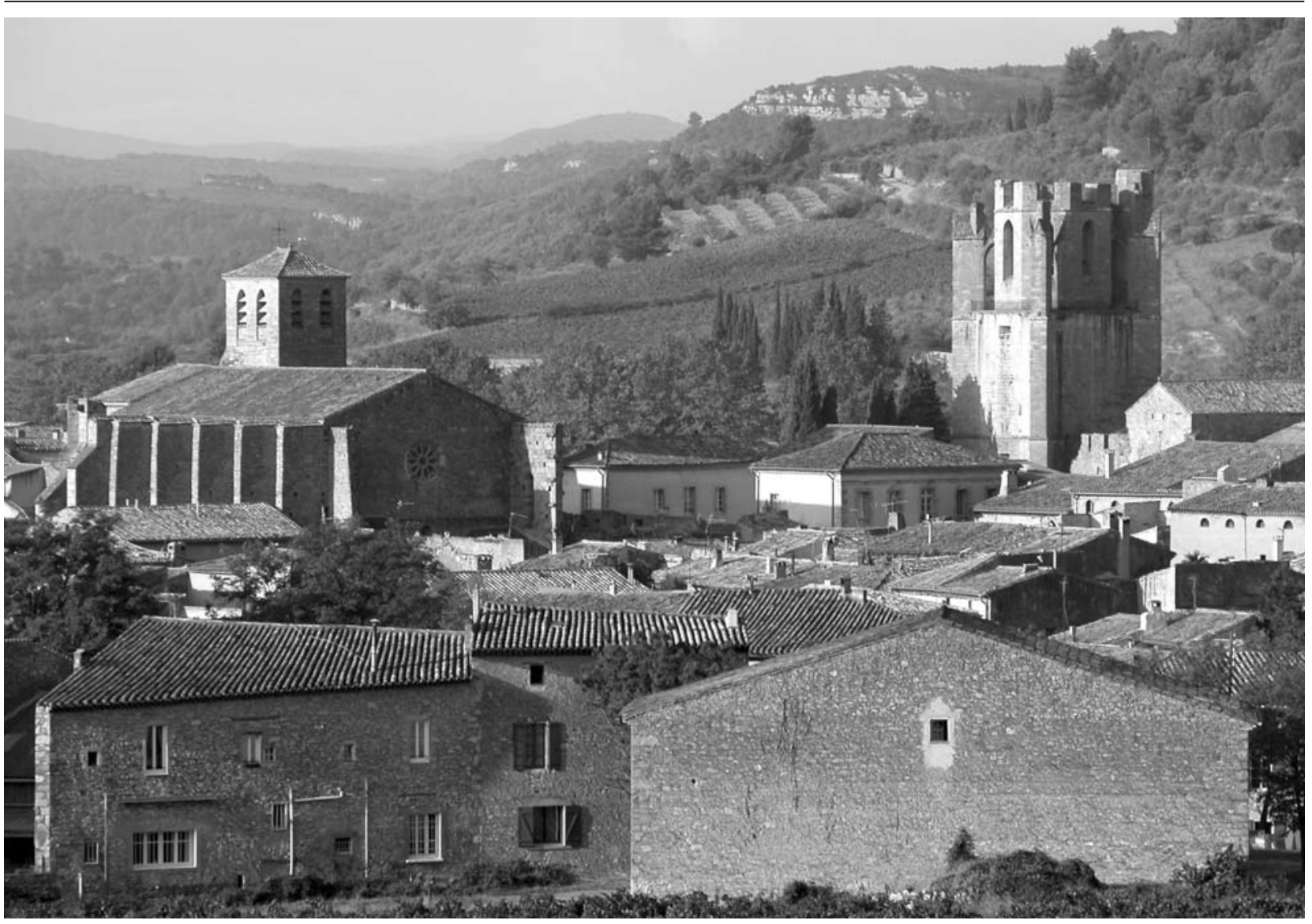

Abbaye de Lagrasse 